\title{
Usaha Mainan Anak Tradisional Desa Karanganyar, Kabupaten Jepara
}

\section{Traditional Childrens Toys Business, Karanganyar Village, Jepara Regency}

Jayanti Putri Purwaningrum*
Imaniar Purbasari
Hutomo Rusdianto
Department of Mathematics
Education, Universitas Muria Kudus,
Kudus, Central Java, Indonesia
'email: jayanti.putri@umk.ac.id
Kata Kunci
Desain produksi
Mainan anak tradisional
Manajemen usaha
Proses produksi
Keywords:
Production design
Traditional children's toys
Business management
Production process
Received: April 2020
Accepted: October 2020
Published: December 2020

\begin{abstract}
Abstrak
Desa Karanganyar merupakan desa sentra penghasil mainan anak tradisional dengan kategori jenis mainan berbasis struktur lingkungan pesisir pantai. Mainan anak tradional ini merupakan salah satu produk unggulan Jepara yang belum banyak dikembangkan oleh Dinas Perindustrian dan Perdagangan serta UMKM di Jepara. Hal ini berakibat pada ketertinggalan pengembangan produk unggulan lokal dan kearifan budaya setempat dibandingkan dengan pengembang mainan anak di daerah lain seperti Purwakarta dan Yogyakarta. Program pengabdian yang dilakukan adalah program pengembangan produk unggulan daerah pada desa sentra penghasil mainan anak tradisional khususnya pada UMKM Mekar Maju. Tujuan khusus dari program ini adalah membantu mitra dalam mengembangkan produk unggulan lokal Desa Karanganyar berupa mainan anak tradional agar memiliki keberagaman jenis mainan yang bernilai edukatif dan ramah anak serta membantu mitra mengembangkan pola manajemen usaha berbasis teknologi. Prioritas dari utama yang disepakati dalam program ini adalah solusi pada masalah proses produksi, desain produk, dan manajemen pemasaran. Hasil dari kegiatan pengabdian ini dapat membantu UMKM dalam (1) peningkatan iklim usaha, (2) peningkatan akses terhadap sumberdaya produktif, (3) pengembangan produk dan pemasaran bagi UMKM, (4) peningkatan daya saing SDM dan UMKM.
\end{abstract}

\begin{abstract}
Karanganyar Village is a village that produces traditional children's toys with toys based on coastal environmental structures. This traditional children's toy is one of Jepara's superior products that has not been developed by the Department of Industry and Trade and MSMEs in Jepara. This results in the underdevelopment of superior local products and local cultural wisdom compared to children's toy developers in other areas such as Purwakarta and Yogyakarta. The service program is a regional superior product development program in traditional children's toy producing centers, especially at Mekar Maju MSMEs. The specific objective of this program is to assist partners in developing superior local products in Karanganyar Village in the form of traditional children's toys so that they have a variety of toys with educational value and childfriendly and helping partners develop technology-based business management patterns. The main priority in this program is solutions to problems in the production process, product design, and marketing management. The results of this service activity can help MSMEs in (1) improving the business climate, (2) increasing access to productive resources, (3) developing products and marketing for MSMEs, (4) increasing the competitiveness of HR and MSMEs.
\end{abstract}




\section{PENDAHULUAN}

Desa Karanganyar merupakan salah satu desa di wilayah Kecamatan Welahan yang berjarak sekitar 25,3 km dari Kabupaten Jepara. Desa Karanganyar merupakan desa yang berpotensi sebagai desa wisata dengan produk unggulan daerahnya adalah mainan anak tradisional berupa kitiran, trotokhan, lele-lelean, dan sebagainya. Namun demikian, industri mainan anak tradisional tersebut bukan merupakan primadona unggulan yang menjadi pusat konsentrasi ekonomi di Kabupaten Jepara (Triyono, 2020). Banyaknya UMKM yang ada di Kabupaten Jepara dengan berbagai keragaman produk ternyata tidak otomatis dapat mengangkat semua sentra industri yang ada.

Usaha pembuatan mainan anak tradisional merupakan usaha yang dijalankan oleh hampir semua warga yang ada di Desa Karanganyar. Rata-rata, mereka menggantungkan penghasilan sehari-hari dari usaha tersebut. Usaha itu merupakan usaha turun temurun warisan nenek moyang yang berasal dari budaya setempat. Sosial budaya Desa Karanganyar masih menganut salah satu tata kota kerajaan zaman Kuno yakni rumah penduduk bergerombol dan sejajar mengikuti alur sungai (Arifin \& Rahman, 2020). Berdasarkan wawancara dengan salah satu ketua Kelompok Pengrajin Mekar Maju, usaha mainan tradisional yang digelutinya selama bertahun-tahun selalu mengalami pasang surut tergantung dari permintaan pasar. Padahal, usaha tersebut merupakan usaha pokok yang menjadi mata pencaharian utama. Adanya interpendensi dan ketergantungan masyarakat Desa Karanganyar dalam usaha ini membuat para pengrajin tidak berani keluar dari sektor domain usaha tersebut.

Dalam perkembangannya, usaha mainan anak tradisional ini tidak begitu naik secara signifikan. Terdapat beberapa permasalahan yang terjadi yang mengakibatkan kurang pesatnya laju industri yang ada, diantaranya adalah:1) tidak adanya administrasi laporan keuangan yang berimbas pada manajemen pengelolaan yang kurang baik; 2) SDM kurang dikarenakan banyak pemuda desa yang lebih memilih bekerja di pabrik; 3) belum adanya promosi via online sehingga pemasarannya masih dilakukan secara manual baik secara langsung, melalui tengkulak maupun bekerjasama dengan mitra dagang yang telah lama berlangganan; 4) proses pembuatan produk masih dibuat dengan cara manual belum memakai mesin; 5) desain produk masih belum ideal dan belum ramah anak; dan 6) produk belum memiliki logo atau labelling. Beberapa persoalan di atas sangat mempengaruhi laju pertumbuhan sentra industri mainan anak yang ada di Desa Karanganyar.

Integrasi masyarakat dalam mencari solusi dari permasalahan-permasalahan yang ada semakin menjadi hal yang sangat penting mengingat bahwa industri ini merupakan salah satu industri warisan nenek moyang yang perlu dijaga kekayaannya untuk dilestarikan (Maridi, 2015). Padahal, jika pengelolaan manajemen pemasaran yang bagus akan memperkuat usaha dalam dunia bisnis dengan promosi sebagai ujung tombaknya. Pada era perkembangan teknologi yang pesat seperti sekarang ini adanya penggunaan teknologi informasi dapat mempermudah pengrajin dalam segi promosi dan system penjualan. Sistem penjualan dengan pemanfaatan teknologi informasi dapat dilakukan tanpa batas waktu (Wibowo, 2014; Hamzah \& Nadjib, 2013). Biayanya pun murah bahkan informasi dapat lebih cepat tersebar luaskan dengan jangkauan yang sangat luas. Pemanfaatan teknologi informasi sebagai media promosi yang efektif dalam meningkatkan omset penjualan (Yap, 2002).

Program pengabdian ini bermitra dengan Kelompok Pengrajin Mekar Maju dengan produk utamanya adalah 
mainan anak tradisional berupa kitiran, trotokhan, dan mainan Tarik seperti lele-lelean, kura-kura, kepiting, dan lain-lain. Adapun kondisi mitra pada segi bahan baku produksi mainan adalah mereka menggunakan cat pewarna mainan dasar yang tidak ramah anak sehingga perlu adanya alternatif pengganti bahan cat yang aman dimainkan anak. Dari segi produksi, alat pencetak mainan masih manual dengan tungku api kompor, alat cetak semen yang dipress dengan tenaga manusia sehingga kualitas produksi mainan belum optimal. Hal tersebut sangat mempengaruhi mutu produk misalnya ukuran produk tidak dapat seragam karena handmade. Begitu pula dengan alat pembentuk bambu pada kitiran masih berupa plat besi atau disebut surut susu randu sehingga kapasitas produksi masih belum efektif. Adapun pemastian mutu produk dari ukuran tidak sama, berakibat ketidaksesuaian kualitas produk dengan permintaan konsumen (Srihadiastuti \& Hidayatullah, 2018; Puspasari et al., 2019).

Dilihat dari desain produk yang saat ini diproduksi, desain yang ada belum mencirikan budaya lokal setempat sehingga produk belum memiliki ciri khusus mainan anak yang diproduksi oleh Desa Karanganyar. Distribusi yang saat ini dilakukan oleh pengrajin adalah dengan melakukan penjualan secara langsung atau diambil oleh masyarakat setempat (pengepul) dan pedagang dari luar kota datang langsung mengambil barang ke pengrajin. Pengelolaan manajemen juga belum teradministrasi dengan baik. Pengrajin tidak memiliki laporan keuangan sehingga administrasi usaha yang dilakukan masih sangat minim.

Berdasarkan hasil forum group discussion (FGD) antara pihak mitra dalam hal ini adalah Kelompok Pengrajin Mekar Maju dan Universitas Muria Kudus disepakati bahwa permasalahan prioritas yang akan dicari solusinya adalah masalah yang berkaitan dengan pada masalah proses produksi, desain produk, dan manajemen pemasaran.

\section{METODOLOGI}

Program pengabdian yang ada tidak hanya bertujuan untuk meningkatkan eksistensi UKM namun masingmasing pihak dapat mendapatkan manfaat dari program yang dijalankan. Adanya sinergi simbiosis mutualisme pada kedua pihak yang saling menguntungkan adalah syarat wajib agar hubungan mitra antara kedua pihak dapat berjalan secara terus menerus (continue dan sustainable). Dengan demikian, berdasarkan masalah yang dialami oleh Kelompok Pengrajin Mekar Maju di Desa Karangnyar maka prioritas solusi yang ditawarkan adalah 1) Pemilihan bahan alternatif cat pewarna yang ramah anak; 2) Pemberian mesin cetak spon, mesin belah dan penghalus bambu; 3) Pemberian usulan desain yang mencirikan budaya setempat; dan 4) Pemberian logo atau labelling produk; dan 5) Pada manajemen pemasaran, dibuatkan website khusus yang dapat membantu usaha penjualan mainan anak tradisonal secara online. Hal ini bertujuan untuk memperluas sekmentasi pasar.

\section{HASIL DAN PEMBAHASAN}

Inovasi Desain Produk, Altenatif Cat Pewarna Ramah Anak Sekaligus Logo atau Labelling Produk

Berdasarkan studi literatur dan FGD yang dilakukan oleh tim pengabdi dan mitra ditemukanlah inovasi produk yang sesuai dengan tujuan pengabdian yaitu produk mainan anak tradisional yang bernilai edukasi dan ramah anak. Desain produk yang dihasilkan disajikan pada Gambar 1 sampai 4 berikut. 


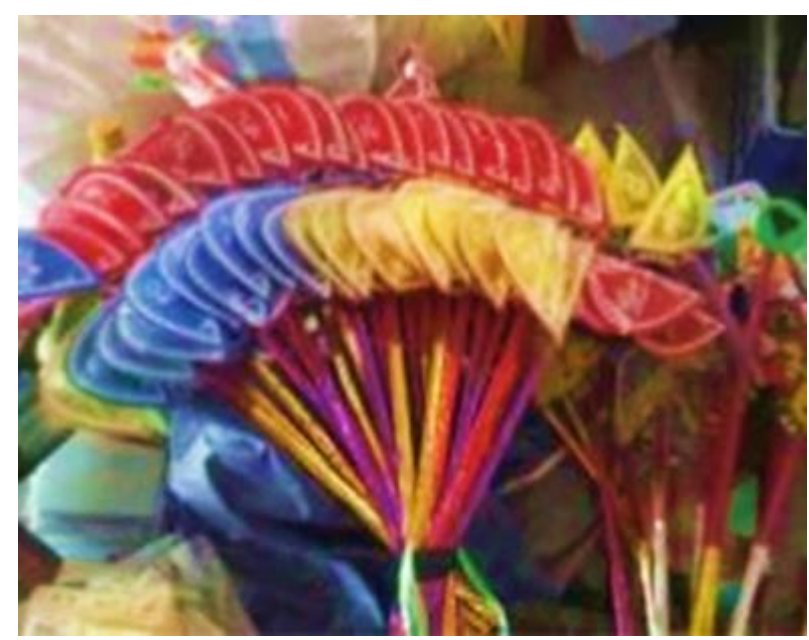

Gambar 1. Desain Lama Mainan Kitiran

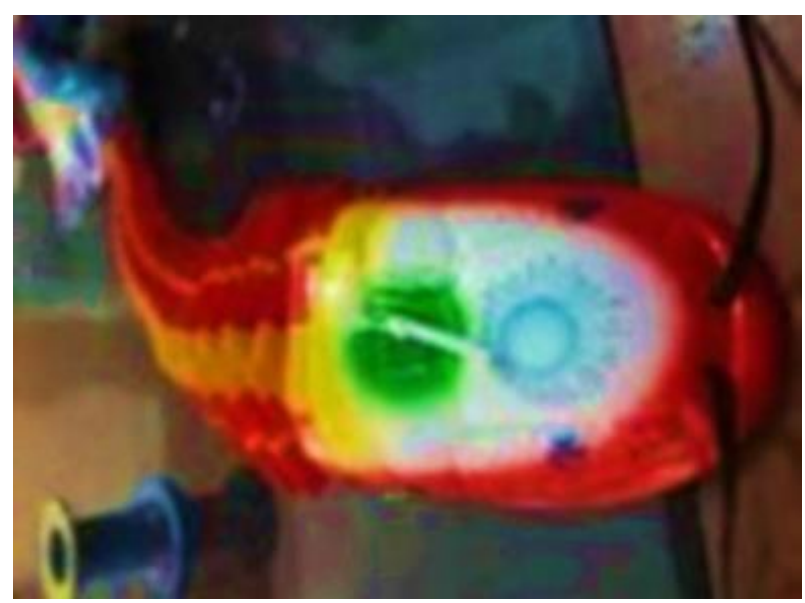

Gambar 2. Desain Lama Mainan Tarik (lele-lelean)

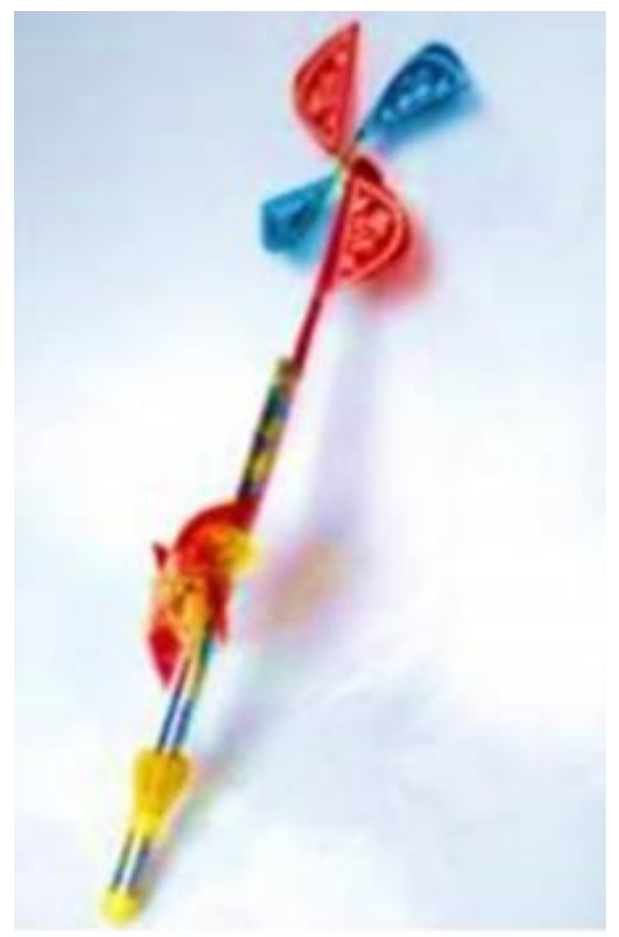

Gambar 3. Desain Baru Mainan Kitiran

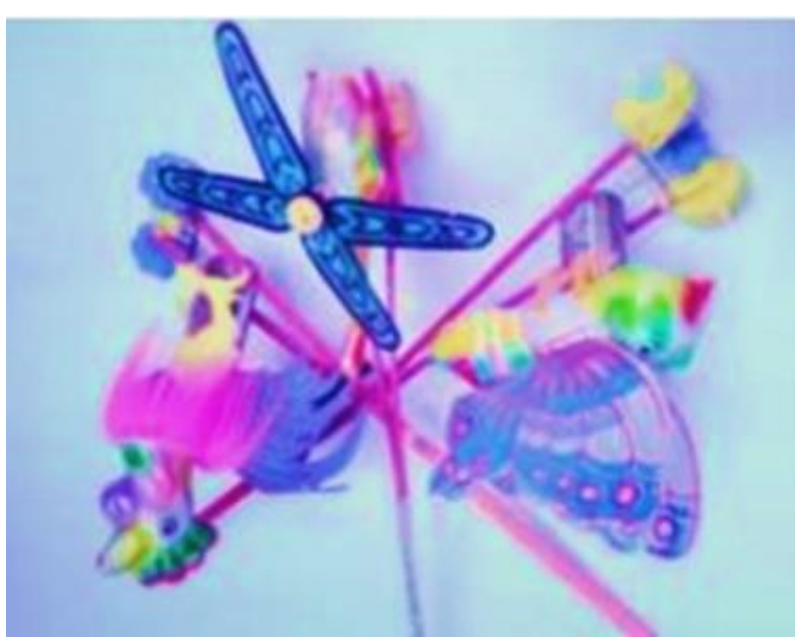

Gambar 4. Desain Bau Mainan Tarik dan Mainan Trotokhan

Berdasarkan tabel di atas, mitra mendapat pendampingan untuk membuat kitiran dengan inovasi pipa dan spon dan membuat mainan tarik dan trothokan dengan cat poster dan clear pilox. Namun, masih terdapat kendala yang ditemukan yakni pada produk kitiran tingkat kerekatan bahan belum optimal, bunyi yang dihasilkan belum kencang seperti produk lama. Sedangkan pada mainan trotokhan kendala yang ditemukan adalah cat poster masih terlalu pekat. Selain itu adanya kerja menambah clear pilox menjadikan proses kerja pengrajin menjadi bertambah.

Terdapat desain baru pada mainan anak yaitu little tiger on the cage dan animasi kartun lainnya yang diproduksi sebagai produk mainan Karanganyar terbaru. Produk desain little tiger on the cage memiliki filosofi sejarah ukir jepara yaitu macan kurung yang menjadi icon kota Jepara. Animasi macan bersifat kartun untuk menarik minat anak mempelajari budaya ukir Jepara. Selain itu desain bentuk mainan anak dibuat dengan struktur kain dan mika tebal yang berwarna sehingga keamanan terhadap mainan anak dapat diproses SNI. Salah satu contoh desain produk baru disajikan pada Gambar 5 berikut. 


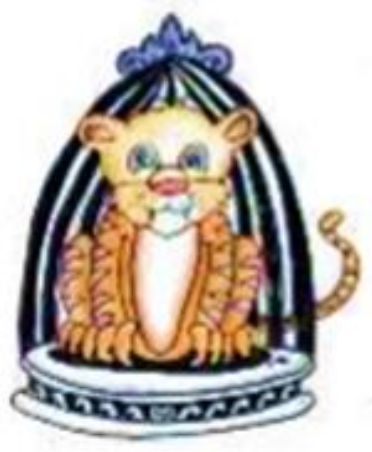

Gambar 5. Desain Produk Baru Little Tiger on The Cage

Desain inovasi produk baru mainan anak disepakati oleh tim pengabdi dan mitra yang ditunjukkan dengan inovasi unsur dan prinsip desain. Pada ukuran disepakati besaran ukuran lebih besar dari produk mainan sebelumnya. Pada warna disepakati corak warna yang primer, tersier dan kuarter dapat digunakan sebagai pemantik kesenangan anak. Pada aspek keberfungsian, disepakati penambahan fungsi, bagian atas kitiran besar susun di bawahnya kitiran kecil, dan bagian bawah atau pegangan ditambahkan rumbai mirip leader drum band serta terompet kecil yang menghasilkan bunyi nyaring. secara tidak langsung desain ini menambahkan 3 fungsi baru pada mainan, sebagaimana disajikan pada Gambar 6. Sementara penilaian inovasi desain yang dihasilkan disajikan pada Tabel I.

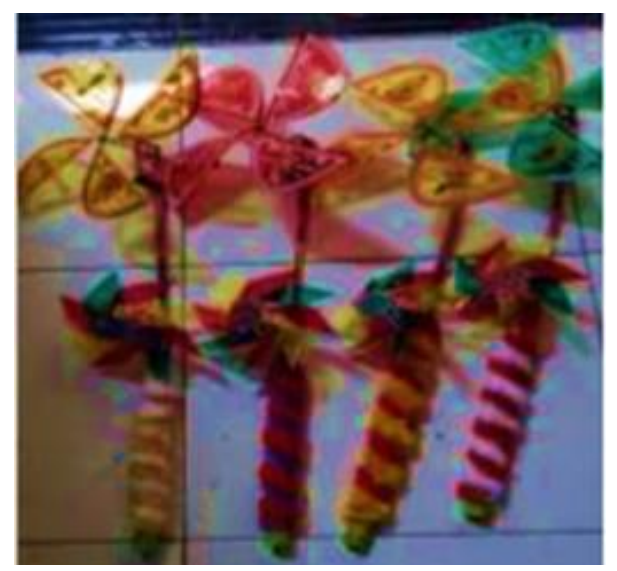

Gambar 6. Inovasi Produk Mainan dengan Desain Produk yang Baru
Tabel I. Inovasi Alternatif Pengganti dan Nilai Edukasi yang Berkarakter Konservatif pada Mainan Anak Tradisional

\begin{tabular}{|c|c|c|c|c|}
\hline No & $\begin{array}{c}\text { Nama } \\
\text { Bahan dan } \\
\text { Item }\end{array}$ & Bahaya & $\begin{array}{c}\text { Usulan } \\
\text { Pengganti }\end{array}$ & $\begin{array}{c}\text { Nilai } \\
\text { Edukasi }\end{array}$ \\
\hline 1 & Cat Spon & $\begin{array}{l}\text { Berbau } \\
\text { Tajam dan } \\
\text { membekas }\end{array}$ & $\begin{array}{l}\text { Cat water } \\
\text { base }\end{array}$ & $\begin{array}{l}\text { Peduli } \\
\text { Lingkungan }\end{array}$ \\
\hline 2 & $\begin{array}{l}\text { Cat sablon } \\
\text { pada } \\
\text { Sayap } \\
\text { pada } \\
\text { Mainan } \\
\text { Anak } \\
\text { Kloto-kan }\end{array}$ & $\begin{array}{l}\text { Mudah } \\
\text { rontok }\end{array}$ & $\begin{array}{l}\text { Cat } \\
\text { sablon } \\
\text { ramah } \\
\text { anak }\end{array}$ & $\begin{array}{l}\text { Peduli } \\
\text { Lingkungan }\end{array}$ \\
\hline 3 & $\begin{array}{l}\text { Cat sablon } \\
\text { pada } \\
\text { Mainan } \\
\text { Tarik Ekor } \\
\text { Lele } \\
\end{array}$ & $\begin{array}{l}\text { Berbau } \\
\text { dan } \\
\text { membekas }\end{array}$ & $\begin{array}{l}\text { Cat water } \\
\text { base }\end{array}$ & $\begin{array}{l}\text { Peduli } \\
\text { Lingkungan }\end{array}$ \\
\hline
\end{tabular}

Adapun inovasi logo atau labeling pada produk disajikan pada Gambar 7.

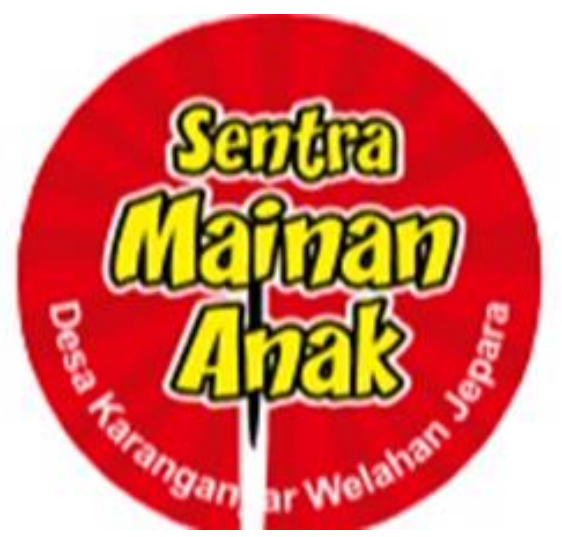

Gambar 7. Inovasi logo atau labelling pada produk

\section{Modernisasi Alat Produksi}

Dalam rangka peningkatan jumlah, kualitas dan kuantitas produksi maka diperlukan adanya modernisasi alat produksi untuk pengrajin. Adapun alat yang telah diberikan sebagai penunjang produksi adalah sebagai berikut:

1. Mesin cetak spon

Mesin cetak spon merupakan alat yang sangat membantu pengrajin dalam proses pengepresan bahan baku mainan anak tradisional yakni spon. Sebelum adanya mesin ini, pengrajin mengepres spon menggunakan cara manual yang bergantung kepada tenaga manusia. Adanya mesin ini dapat 
meningkatkan proses produksi produk mainan menjadi 5 kali lipat. Kualitas dari produk yang dihasilkan dari segiukuran pun dapat seragam sebab proses produksi tidak lagi handmade. Produk mesin cetak disajikan pada Gambar 8.

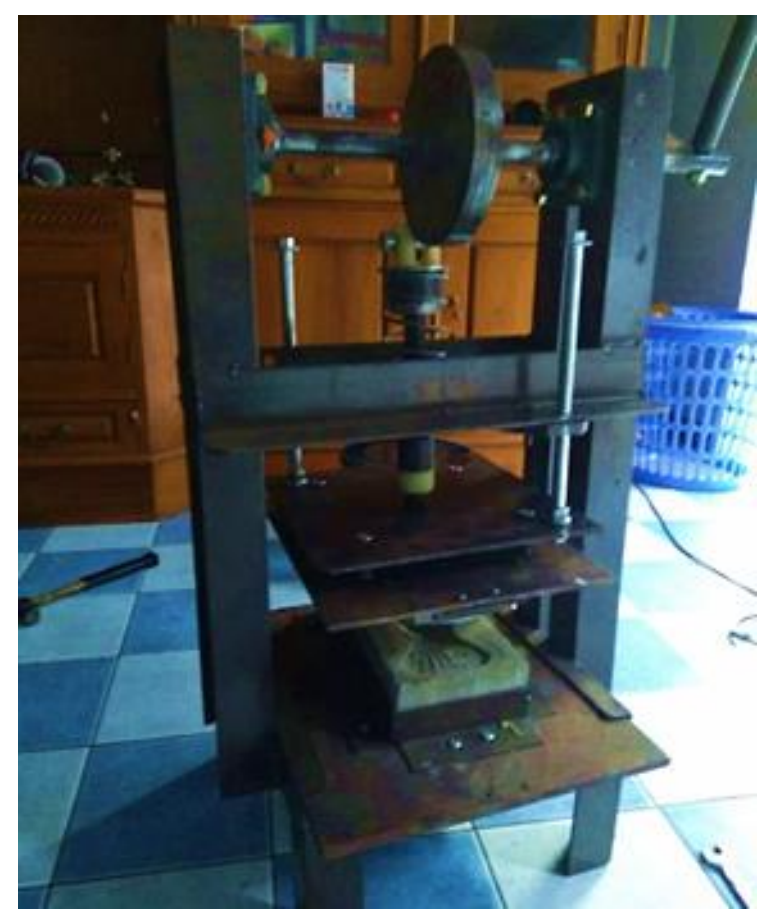

Gambar 8. Mesin Cetak Spon

2. Mesin belah dan penghalus bamboo

Mesin belah dan penghalus bambu merupakan desain rancang bangun yang pertama kali dibuat sesuai dengan kebutuhan pengrajin sehingga belum ada di pasaran. Pemilihan bahan dan proses perakitan dilakukan dengan metode trial and eror dengan mengupayakan suku cadang yang mudah dicari di pasaran.

Tim berharap dengan bahan yang mudah dicari, maintenance terhadap mesin dapat dilakukan dengan baik oleh mitra. Bahan sederhana namun mudah dicari ini menimbulkan mesin terproduksi memiliki berbagai kelebihan dan kekurangan. Mesin belah bambu dapat digunakan untuk sekali membelah bambu, bambu akan terbelah menjadi 5 potong. Sedangkan mesin penghalus bambu menghasilkan serutan bambu sesuai dengan ketebalan yang diinginkan dalam setiap potong bambunya. Ini berarti kerja mesin menghasilkan lima kali lipat pekerjaan membelah dan menghaluskan bambu. Selain itu dampak kesehatan bagi pekerja akibat debu dari pemotongan dan penghalusan bambu dapat diminimalisir.

Kendala utama terdapat pada pisau pembelah bambu yang perlu diatur tingkat ketebalan bambu serta tekanan atau dorongan terhadap masuknya bambu. Beberapa kali mesin masih macet dikarenakan pisau pembelah tersumbat serutan bambu. Upaya perbaikan dilakukan dengan meregangkan per dan mengatur mata pisau agar sisa serutan bambu tidak menghambat kinerja mesin. Pengetahuan ini juga disampaikan kepada mitra agar mengetahui seluk beluk dan kerja mesin. Gambar mesin belah dan penghalus bamboo disajikan pada Gambar 9 .

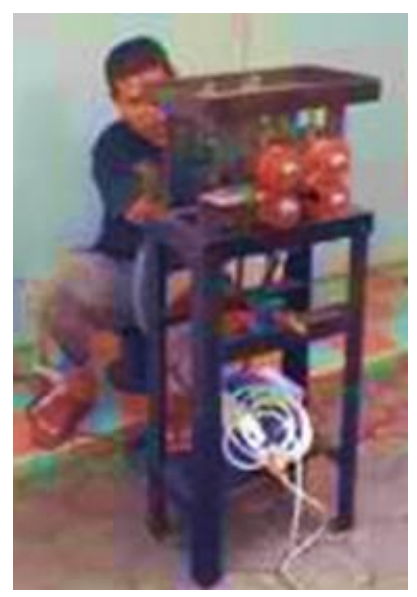

Gambar 9. Mesin Belah dan Penghalus Bambu

Inovasi Manajemen Pemasaran

Adapun inovasi manajemen pemasaran yang dilakukan yakni membuatkan website yang bertujuan untuk meningkatkan jangkauan pemasaran agar lebih luas. Selain mengadakan pelatihan dalam menggunakan website, tim pengabdi juga membuat modul petunjuk penggunaan website bagi mitra. Pelatihan penggunaan website sebagai media promosi merupakan langkah 
yang efektif dalam membantu peningkatan kemampuan pengrajin mengelola manajemen pemasaran berbasis online (Wardani \& Endahati, 2019). Bentuk halaman website disajikan pada Gambar 10 dan 11.

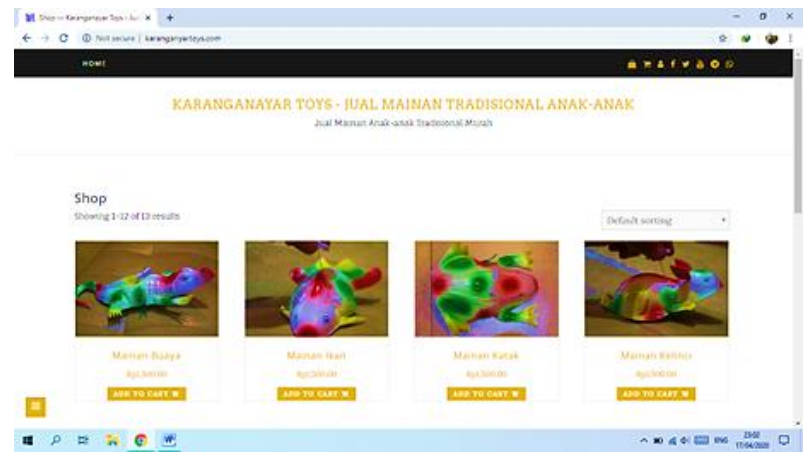

Gambar 10. Tampilan Website Via Komputer

\section{슬}

KARANGANAYAR TOYS - JUAL MAINAN TRADISIONAL ANAKANAK

Jual Mainan Anak-anak Tradistonal Murah
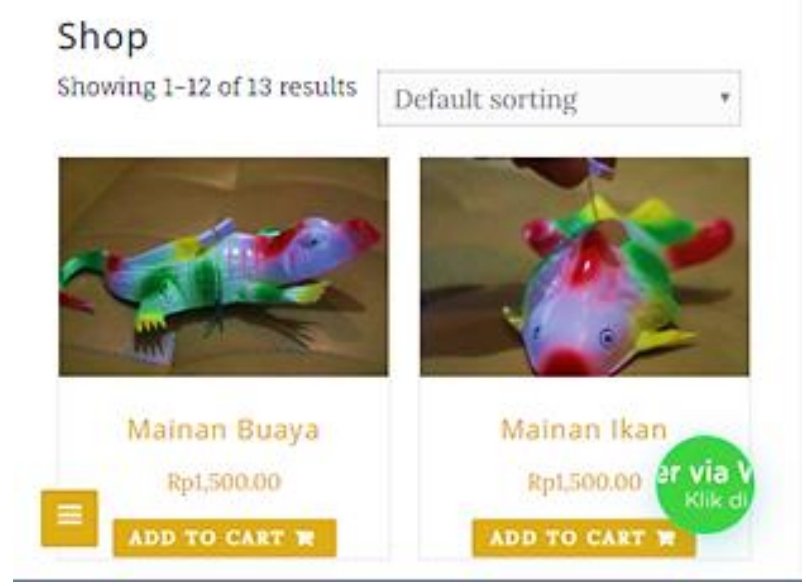

Gambar 11. Tampilan Website Via Handphone

Darnis dan Azdy (2019) berpendapat bahwa promosi via website merupakan alternatif media promosi yang efektif di era milineal. Saat ini, website merupakan media sosial yang memiliki banyak pengaruh dalamjangkauan pemasaran (Supuwiningsih et al., 2018).
Beberapa program pengabdian sudah dijalankan, baik pada masalah proses produksi, desain produk, dan manajemen pemasaran. Beberapa capaian telah dapat diukur. Berikut capaian yang telah dilakukan.

1. Cat yang digunakan ramah anak sehingga aman untuk dimainkan oleh anak.

2. Proses pembuatan produk lebih cepat. Jumlah yang dihasilkan dalam sehari juga memiliki peningkatan sebesar lima kali lipat. Produk yang dihasilkan pun memiliki kualitas dan ukuran yang sama. Adanya alat mempermudah pengrajin dalam proses produksi. Mereka tidak lagi memproduksi mainan anak tradisional secara manual namun sudah menggunakan mesin-mesin pembantu.

3. Jangkauan pemasaran lebih luas karena adanya media website yang digunakan dalam promosi.

4. Munculnya produk-produk dengan desain baru yang khas dan mencirikan budaya setempat yang sekaligus dilengkapi dengan logo atau labelling.

5. Adanya bisnis plan yang jelas tentang orientasi pasar dengan memanfaatkan berbagai inovasi.

\section{KESIMPULAN}

Secara umum, program pengabdian yang telah dilakukan sesuai dengan rencana. Kerjasama yang baik terjalin antara mitra dan tim pelaksana sangat berpengaruh terhadap kegiatan yang dijalankan. Adapun luaran dari kegiatan yang dicapai adalah alternatif cat pewarna yang ramah anak; modernisasi mesin produksi yakni mesin cetak spon, mesin belah dan penghalus bambu; adanya inovasi desain produk yang khas dan bercirikan budaya lokal setempat sekaligus dilengkapi dengan logo atau labelling; dan website pemasaran produk sebagai media promosi. 


\section{UCAPAN TERIMA KASIH}

Penulis mengucapkan terimakasih kepada Kementerian Riset dan Teknologi/ Badan Riset dan Inovasi Nasional atas dukungan berupa dana hibah PPPUD sehingga program pengabdian pada masyarakat dapat terlaksana. Ucapan terimakasih juga kami ucapkan kepada Rektor dan kepala LPPM Universitas Muria Kudus atas bantuannya dalam memberikan perhatian dan dorongan untuk melaksanakan program penelitian ini.

\section{REFERENSI}

Arifin, Z., Rahman, F. 2020. Living in the riverbanks: Case of the Ogan malay community settlement, South Sumatera. Etnosia : Jurnal Etnografi Indonesia. 5(1):33-49. https://doi.org/10.31947/etnosia.v5i1.8467

Darnis, F., Azdy, R.A. 2019. Pemanfaatan Media Informasi Website Promosi (e-Commerce) sebagai Upaya Peningkatan Pendapatan UMKM Desa Pedado. In SINDIMAS Seminar Nasional Hasil Inovasi Pengabdian Masyarakat. 275-278. Pontianak: STMIK Pontianak. http://dx.doi.org/10.30700/sm.v1i1.584

Hamzah, D., Nadjib, M. 2013. Pemanfaatan Internet Sebagai Media Promosi Pemasaran Produk Lokal Oleh Kalangan Usaha Di Kota Makassar. Kareba : Jurnal Ilmu Komunikasi. 2(1):30-40.

Maridi, M. 2015. Mengangkat Budaya dan Kearifan Lokal dalam Sistem Konservasi Tanah dan Air. Proceeding Biology Education. 12(1):20-39.

Puspasari, A., Mustomi, D., Anggraeni, E. 2019. Proses Pengendalian Kualitas Produk Reject dalam Kualitas Kontrol PT. Yasufuku Indonesia Bekasi. Widya Cipta : Jurnal Sekretari dan Manajemen. 3(1):71-78. https://doi.org/10.31294/widyacipta.v3i1.50 88

Srihadiastuti, R., Hidayatullah, D.S. 2018. Analisis Penyebab Kegagalan Mendirikan Usaha Baru Pada Para Lulusan Program Wirausaha Baru Jawa Barat Kelas Ide Bisnis. Jurnal Ekonomi Pendidikan dan Kewirausahaan. 6(1):31-44. http://dx.doi.org/10.26740/jepk.v6n1.p31-44
Supuwiningsih, N.N., Sumadi, N.K., Muryatini, N. 2018. PKM Kelompok Penjahit Kebaya Desa Meliling Tabanan. Widyabhakti : Jurnal Ilmiah Populer. 1(1):54-60.

Triyono, J. 2020. Strategi Pengembangan Desa Wisata Tenun Ikat Troso Di Jepara, Jawa Tengah. Kepariwisataan: Jurnal Ilmiah. 14(2):84-92.

Wardani, S., Endahati, N. 2019. Pendampingan Kelompok Budidaya Mina Jaya Dusun Gupawarak Desa Sendangsari Bantul. Wikrama Parahita : Jurnal Pengabdian Masyarakat. 3(2):47-51. https://doi.org/10.30656/jpmwp.v3i2.1502

Wibowo, E.A. 2014. Pemanfaatan Teknologi ECommerce Dalam Proses Bisnis. EQ (Equilibiria) : Jurnal Fakultas Ekonomi. 1(1):95108.

Yap, E.Y. 2002. Enabling E-Commerce Growth Through the Social Construction of a Virtual Community's Culture. Journal of Electronic Commerce Research. 3(4):279-294. 